\title{
Genetic diversity among natural populations of Ottelia acuminata (Gaghep.) Dandy revealed by ISSR
}

\author{
H. Y. Zhang ${ }^{1,2}$, K. Tian ${ }^{1 *}$, Y. Yu ${ }^{2}$, L. Y. Li ${ }^{1}$ and Y. M. Yang ${ }^{1}$ \\ ${ }^{1}$ National Plateau Wetland Research Center, Southwest Forestry University, White Dragon Temple, Kunming, Yunnan \\ Province, 650224, People's Republic of China. \\ ${ }^{2}$ Biotechnology Laboratory, Southwest Forestry University, White Dragon Temple, Kunming, Yunnan Province, 650224, \\ People's Republic of China. \\ Accepted 19 October, 2009
}

\begin{abstract}
Ottelia acuminata (Gagnep.) Dandy, an aquatic species of the Hydrocharitaceae, is endemic to China. A performance comparison of genetic diversity of 4 natural populations was conducted to investigate whether or not water pollution in their habitats has anything to do with this species being endangered. A total number of 120 O. acuminate accessions were analyzed, by amplification of their DNAs with 15 primers (ISSR). Thirteen primers were scored and 214 bands were detected, of which 170 were polymorphic $(79.44 \%)$. The results showed that the genetic indices in polluted Jian Lake group were always the smallest ones, when compared with those of the other groups. It indicated that the polluted water did affect the genetic diversity of $O$. acuminate populations. And ISSRs seemed to be effective tools for detecting genetic variation among $O$. acuminate geographical groups.
\end{abstract}

Key words: Ottelia acuminate, ISSR, genetic diversity, DNA polymorphism.

\section{INTRODUCTION}

Ottelia acuminate (Gaghep.) Dandy, an economically and ecologically important swamp monocot, is mainly distributed in Southwest of China, having been recorded at Yunnan, Hainan, Sichuan, Guizhou and Guangxi Provinces. It has been used as ornamental and edible plants. In recent years, natural populations of $O$. acuminate become more and more rare and it has become one of the endangered species in China. The endangered situation of this endemic species had been mainly attributed to water pollution in their habitats. However, there is little evidence to support that water pollution affects the genetic diversity of $O$. acuminate.

Genetic diversity allows species to adjust to a changing world, which is caused by both natural and human factors. Understanding genetic diversity with the species is essential for establishing effective and efficient conservation and breeding practices (Chaveerach et al., 2006). Inter-simple sequence repeats (ISSRs) is a type of DNA

\footnotetext{
*Corresponding author. E-mail: tlkunp@swfc.edu.cn.
}

for DNA amplifications (Zietkiewicz et al., 1994; Sánchez et al., 1996). Under conditions of adapted amplifications, the DNA fragments were separated in agarose gel or acrylamide gel (Farès et al., 2009). Revealed polymorphism is primarily of presence/ absence type, as for the RAPD, but corresponds sometimes to differences in lengths of fragment, as for the microsatellites (Sylvain et al., 2000). ISSR is a dominant molecular marker revealed in mass, and has been proposed as a source of genetic markers which overcomes the technical limitations of restriction fragment length polymorphism (RFLP) and random amplified polymorphic DNA (RAPD) (Ratnaparkhe et al., 1998). Up to date, ISSRs have been used reliably as molecular markers in genetic studies for various plants such as popcorn (Kantey et al., 1995), rice (Blair et al., 1999), potato (Mc Gregor et al., 2000), coffea (Paulo et al., 2003), Musa acuminata (Racharak and Eiadthong, 2007) and pistochio tree (Farès et al., 2009).

In this report the ISSR procedure was used to assess the amount of polymorphism detected among natural groups of $O$. acuminate and to investigate whether or not water pollution in their habitats is one of the reasons for this species being endangered. 
Table 1. The origins of $O$. acuminate materials.

\begin{tabular}{|c|c|c|c|}
\hline Number & Origin & Geographical number & Water condition \\
\hline $01-30$ & Yianyuchang & I & unpolluted \\
$31-60$ & Miaopang & II & unpolluted \\
$61-90$ & Jian Lake & III & polluted \\
$91-120$ & Shuigulou & IV & unpolluted \\
\hline
\end{tabular}

\section{MATERIALS AND METHODS}

\section{Plant materials}

One hundred and twenty accessions of $O$. acuminate obtained from three headwaters of Gemei river and Jian lake in Yunnan province, southwest of China, were used for evaluation in this study. Number and origin of the accession of $O$. acuminate were showed in Table 1.

\section{DNA extraction}

DNA was extracted from shoots by the CTAB method (Liu et al., 2009). Samples were ground to powder in liquid nitrogen, using a mortar and pestle. The powder was transferred to a $25 \mathrm{ml}$ sterile Falcon tube with $10 \mathrm{ml}$ of CTAB buffer. The extraction buffer consisted of $2 \%(\mathrm{w} / \mathrm{v})$ CTAB (cetyltrimethyl ammonium bromide, Sigma), $1.5 \mathrm{M} \mathrm{NaCl}, 20 \mathrm{mM}$ EDTA, $100 \mathrm{mM}$ Tris- $\mathrm{HCl} \mathrm{pH} 9.5$ and $0.2 \%(\mathrm{v} / \mathrm{v}) \beta$-mercaptoethanol. After incubating the homogenate at $65^{\circ} \mathrm{C}$ for $1 \mathrm{~h}$ an equal volume of chloroform was added and centrifuged at $10,000 \mathrm{rpm}$ for $20 \mathrm{~min}$. DNA was precipitated with $1 / 10$ volume $(\mathrm{ml})$ of $3 \mathrm{M}$ sodium acetate and an equal volume of isopropanol followed by centrifugation at $10,000 \mathrm{rpm}$ for $10 \mathrm{~min}$. The DNA pellet was washed with $70 \%$ ethanol, air-dried, and resuspended in TE-buffers (10 mM Tris pH 8.0 and $0.1 \mathrm{mM}$ EDTA). DNA quantity was estimated spectrophotometrically by measuring absorbance at $260 \mathrm{~nm}$. DNA samples were diluted in sterile deionized water and maintained at $-20^{\circ} \mathrm{C}$.

\section{DNA analysis}

ISSR primers were synthesized by Sangon (Sangon, Shanghai, China) according to the sequence reported by Yang et al. (2005). Amplification was performed in volumes of $20 \mu \mathrm{l}$ containing $2 \mu \mathrm{l}$ of the $10 \mathrm{x}$ buffer and $100 \mathrm{mM}$ each of dNTPs, $0.4 \mathrm{mM}$ primer, $25 \mathrm{ng}$ genomic DNA and 1 unit of polymerase. The reaction mixture was overlaid with $40 \mu \mathrm{l}$ mineral oil. Amplifications were carried out using a 2400 Perkin-Elmer Thermal Cycles programmed for 40 cycles as follows: $30 \mathrm{~s}$ at $94^{\circ} \mathrm{C}, 30 \mathrm{~s}$ at $50^{\circ} \mathrm{C}, 1.5 \mathrm{~min}$ at $72^{\circ} \mathrm{C}$, with an initial melting of $6 \mathrm{~min}$ at $94^{\circ} \mathrm{C}$ and a final extension of $6 \mathrm{~min}$ at $72^{\circ} \mathrm{C}$. Amplification products were analyzed by electrophoresis in a $1.5 \%$ agarose gel with $1 \times$ TAE buffer $(0.004 \mathrm{M}$ Tris-acetate and $0.002 \mathrm{M}$ EDTA).

Individual ISSR fragments for each primer-genotype combination were scored as 1 (presence) or 0 (absence) and a note of their sizes was made. The set of fragments co-migrating across the 120 accessions of $O$. acuminate was referred to as a band. The calculations of index of genetic diversity were performed with the POPGEN (Yeh et al. 1999) software package. The calculations of pairwise matrix of percent agreement were performed using STASTICA (version 6.1, StatSoft, Tulsa, OK). AMOVA analysis was performed with the software package Arlequin (Schneider et al., 2000).

\section{RESULTS AND DISCUSSION}

Fifteen primers were used in this study, 2 produced amplification products that were too faint to score. Thus 13 out of 15 primers were scored (Table 2). A total of 214 bands were scored from the comparison of amplifications with 13 primers of DNAs from 120 O. acuminate accessions, with an average of 16.46 bands scored per primer. Seven to thirty-five bands generated by a single primer of variable lengths were detected. Portions of gels showing typical amplification products were shown in Figures 1 and 2. More than four fifths of the bands were larger than 200 but smaller than 1500 base pairs and less than $10 \%$ larger than 2000 base pairs, that is, mostly of small and medium size.

Among all 214 loci detected, 170 of them were polymorphic (79.44\%). In different geographical groups, the frequency of polymorphic bands varied from 77.83 to 78.47\%; number of loci amplified ranged from 203 to 209; and the range of polymorphic loci number was from 158 to 164 (Table 3). Observed number of alleles (Kimura and Crow, 1964) ranged from 1.8421 to 1.8934; Effective number of alleles varied from 1.7509 to 1.7611 ; Nei's index (Nei, 1973) was from 0.2599 to 0.2776 ; and Shannon's index (Lewontin, 1972) was from 0.4013 to 0.4401 (Table 4). It was worth noting that the genetic indices in geographical group of Jian Lake were always the smallest ones, when compared with those of the other groups. It indicated that the polluted water did affect the genetic diversity of $O$. acuminate populations.

In this study, the average number of bands per primer detected over all the 15 primers tested was 11.33 polymorphic and 14.27 totally (invariant plus polymorphic). A pairwise matrix of percent agreement between all the analyzed plants was obtained (data not shown) and between 63.53 and $85.35 \%$ of all fragments were shared between plants of the same group. These results suggested the existence of a great number of genetic variations among $O$. acuminate accessions. Existence of high genetic diversity within $O$. acuminate populations may be attributed to cross-pollination. When the genetic variation of the accessions was partitioned by AMOVA, $59.42 \%$ of the variation was found among the accessions that had different origins while $40.58 \%$ was found among the ones that had the same origins. Both of the variation figures, within and among the origins, were highly significant $(P<0.001)$ (data not shown). 
Table 2. List and DNA sequences of the primers used for ISSR analysis, indicating the number of bands observed.

\begin{tabular}{|c|l|c|c|}
\hline Primer & \multicolumn{1}{|c|}{ Sequence } & Total number of bands scored & Number of polymorphic bands \\
\hline A1 & TGGATGGATGGATGGATGGA & 7 & 6 \\
A3 & GACAGACAGACAGACAGACA & 9 & 6 \\
A7 & AGAGAGAGAGAGAGAGAGAGT & 12 & 11 \\
A9 & CTCTCTCTCTCTCTCTCTCTG & 19 & 14 \\
A10 & CTCTCTCTCTCTCTCTCTCTT & 12 & 12 \\
A13 & GTGTGTGTGTGTCC & 35 & 29 \\
A17 & GTGGTGGTGGTGGC & 14 & 13 \\
A22 & CACACACACACAGT & 28 & 22 \\
U818 & 5' CACACACACACACACAG 3' & 15 & 13 \\
U825 & 5' ACACACACACACACACT 3' & 21 & 14 \\
U827 & 5' ACACACACACACCG 3' & 11 & 7 \\
U841 & 5' GAGAGAGAGAGAGAGAYC 3' & 18 & 13 \\
U866 & 5' CTCCTCCTCCTCCTC 3' & 13 & 10 \\
Total & & 214 & 170 \\
\hline
\end{tabular}

$\mathrm{Y}=(\mathrm{C}, \mathrm{T})$

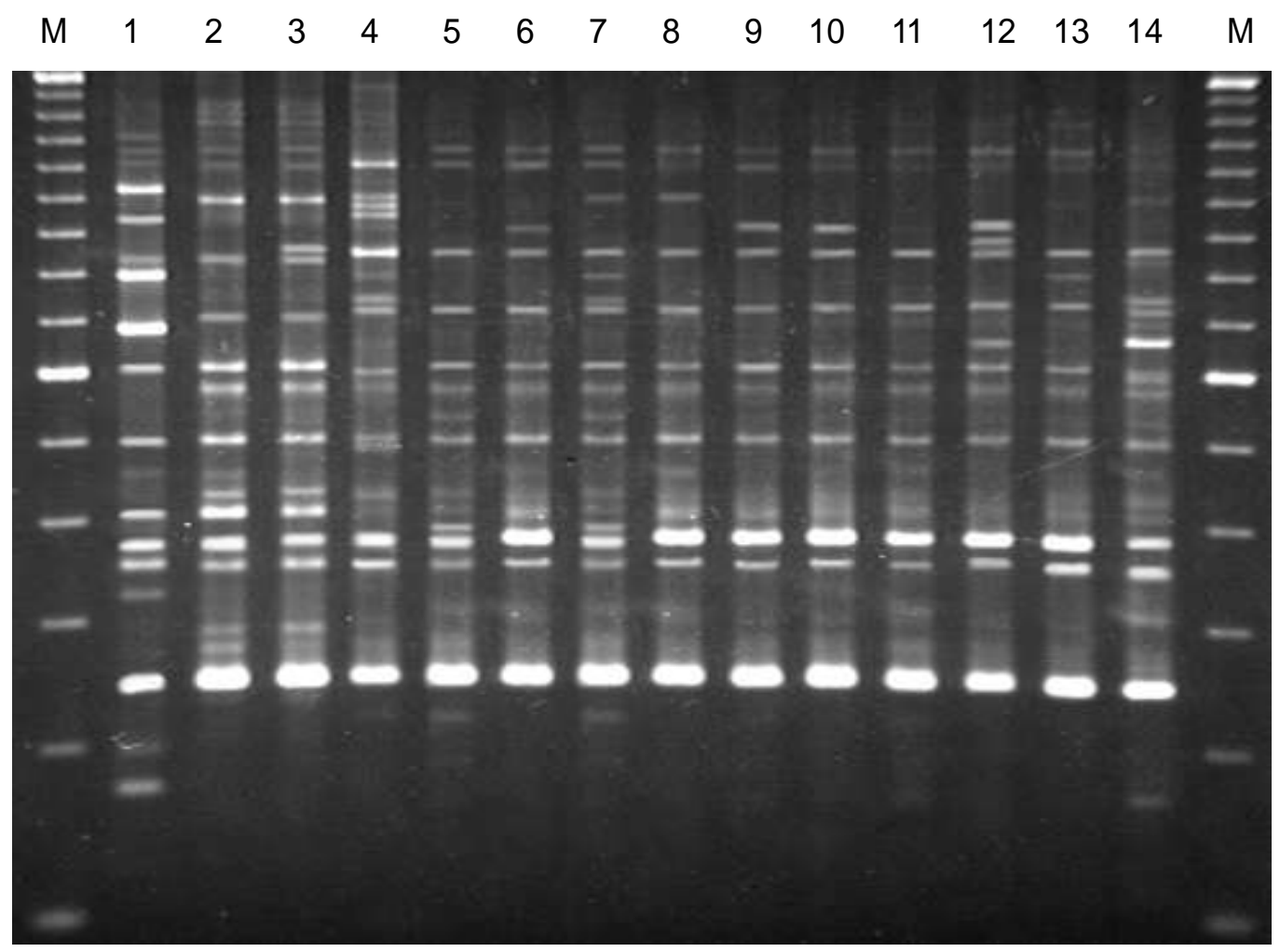

Figure 1. Amplification products of some O. acuminate accessions (the primer was A13).

The polymorphic bands were 170 (79.44\%) and in average the band polymorphism per genotype was $6.3 \%$. The use of primers selected for faithful reproduction of higher polymorphism in the target group of genotypes could further increase the efficiency and the applications of the ISSR approach. The results showed that A13 and A22 were most suitable for revealing the genetic variance among $O$. acuminate accessions. ISSRs have the advantage that the material is processed by an efficient and inexpensive technique without requiring prior knowledge of the genome. This is particularly relevant for the $O$. acuminate, whose genome analysis data is limited. Our results confirm the ISSR technology as a reliable, rapid and inexpensive screening method to discriminate $O$. 


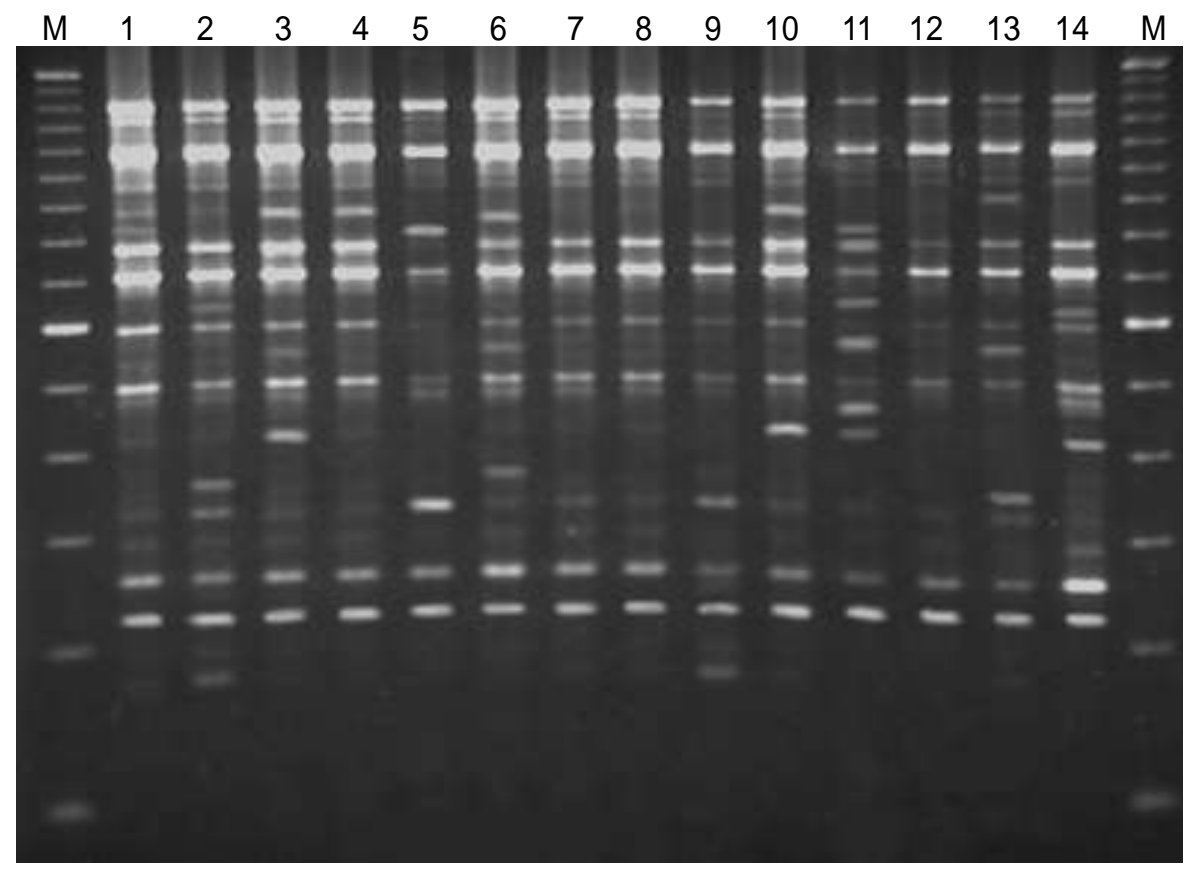

Figure 2. Amplification products of some 0 . acuminate accessions (the primer was A22).

Table 3. Polymoriphic loci among different geographical groups.

\begin{tabular}{|c|l|c|c|c|c|}
\hline No. & $\begin{array}{c}\text { Geographical } \\
\text { groups }\end{array}$ & $\begin{array}{c}\text { Number of } \\
\text { samples }\end{array}$ & $\begin{array}{c}\text { Number } \\
\text { of loci }\end{array}$ & $\begin{array}{c}\text { No. of } \\
\text { polymorphic }\end{array}$ & $\begin{array}{c}\text { Percent of } \\
\text { polymorphic (\%) }\end{array}$ \\
\hline $1-16$ & Yianyuchang & 30 & 209 & 164 & 78.47 \\
$17-32$ & Miaopang & 30 & 208 & 162 & 77.88 \\
$33-48$ & Jian Lake & 30 & 203 & 158 & 77.83 \\
$49-64$ & Shuigulou & 30 & 205 & 160 & 78.05 \\
\hline & Mean & 30 & 206.25 & 161 & 78.06 \\
\cline { 2 - 6 } & Total & 120 & 214 & 170 & 79.44 \\
\hline
\end{tabular}

Table 4. The genetic diversity among the different geographical groups.

\begin{tabular}{|l|c|c|c|c|}
\hline Geographical groups & Yianyuchang & Miaopang & Jian Lake & Shuigulou \\
\hline $\mathrm{Ne}^{*}$ & 1.8934 & 1.8579 & 1.8421 & 1.8618 \\
$\mathrm{Na}^{*}$ & 1.7602 & 1.7611 & 1.7509 & 1.7559 \\
$\mathrm{H}^{*}$ & 0.2776 & 0.2640 & 0.2599 & 0.2608 \\
$\mathrm{I}^{*}$ & 0.4401 & 0.4209 & 0.4013 & 0.4204 \\
\hline
\end{tabular}

${ }^{*} \mathrm{Ne}=$ Effective number of alleles [Kimura and Crow (1964)].

${ }^{*} \mathrm{Na}=$ Observed number of alleles.

${ }^{*} \mathrm{H}=$ Nei's (1973) gene diversity.

${ }^{*} \mathrm{I}=$ Shannon's Information index [Lewontin (1972)].

acuminate genotypes.

\section{ACKNOWLEDGEMENTS}

The study was supported by grants from the National Basic Research Program of China (973 Program) (No. 2008CB417210) and the Science and Technology
Planning Project of Yunnan Province (Grant No. 2008CA006).

\section{REFERENCES}

Blair MW, Panaud O, Mc Couch SR (1999). Inter simple sequence repeat (ISSR) amplification for analysis of microsatellite motif 
frequency and fingerprinting in rice (Oryza sativa). Theor. Appl. Genet. 98: 780-792.

Chaveerach A, Tanomtong A, Sudmoon R, Tanee T (2006). Genetic diversity among geographically separated populations of Nepenthes mirabilis. Biologia Brat. 61: 295-298.

Farès K, Guasmi F, Touil L, Triki T, Ferchichi A (2009). Genetic diversity of pistochio tree using inter-simple sequence repeat markers ISSR supported by morphological and chemical markers. Biotechnolgy, 8: 24-34.

Kantey RV, Zeng XP, Bennetzen JL, Zehr BE (1995). Assessment of genetic diversity in dent and popcorn (Zea mays L.) inbred lines using Inter-simple sequence repeat (ISSR) amplification. Mol. Breed. 1: 365-373.

Kimura M, Crow JF (1964). The number of alleles that can be maintained in a finite population. Genetics, 49: 725-38.

Lewontin RC (1972). Testing the theory of natural selection. Nature, 236: 181-182.

Liu XZ, Yang YM, He CS, Li HL, Zhang HY (2009). A RAMP Marker Linked to the Tobacco Black Shank Resistant Gene. Afr. J. Biotechnol. 8: 2060-2063.

Mc Gregor CE, Lambert CA, Greyling MM, Louw JH, Warnich LA (2000). Comparative assessment of DNA fingerprinting techniques (RAPD, ISSR, AFLP and ISSR) in tetraploid potato (Solanum tuberosum L.). Euphytica, 113: 135-144.

Nei M (1973). Analysis of gene diversity in subdivided populations. Proc. Natl. Acad. Sci. USA, 70: 3321-3323.

Paulo M, Ruas C, Ruas F, Leandro R, Valdemar P, Carvalho AE, Tumoro S (2003). Genetic relationship in coffea species and parentage determination of interspecific hybrids using ISSR (InterSimple Sequence Repeat). Genet. Mol. Biol. 26: 319-327.

Racharak P, Eiadthong W (2007). Genetic relationship among subspecies of Musa acuminata Colla and A-genome consisting edible cultivated bananas assayed with ISSR markers. Songklanakarin J. Sci. Technol. 29: 1479-1489.
Ratnaparkhe MB, Tekeoglu M, Muehlbauer (1998). Inter-simplesequence-repeat (ISSR) polymorphisms are useful for finding markers associated with disease resistance gene clusters. Theor. Appl. Genet. 97: 515-519.

Sánchez de la Hoz MP, Dávila JA, Loarce Y, Ferrer E (1996). Simple sequence repeats primers used in polymerase chain reaction amplifications to study genetic diversity in barley. Genome, 39: 112117.

Schneider S, Roessli D, Excoffier L (2000). Arlequin ver. 2.000: a Software for Population Genetic Data Analysis. Genetics and Biometry Laboratory, University of Geneva, Geneva, Switzerland (Available at URL http://anthropologie.unige.ch/arlequin/).

Sylvain S, Patricia FR, Emilce P, Daniel P (2000). Molecular markers for genetic resource analysis and plant breeding. Cahiers Agric. 4: 311 327.

Yang CP, Wei L, Jiang J, Liu GF, Zhou GY (2005). Analysis of Genetic Diversity for Nineteen Populations of Pinus sibirica Du Tour with Technique of ISSR. J. Northeast For. Univ. 33: 1-3.

Yeh FC, Yang RC, Boyle TBJ (1999). Popgene version 1.31: Microsoft Windows-based freeware for population genetic analysis. Molecular Biology and Biotechnology Centre, University of Alberta, and Centre for International Forestry Research, Canada.

Zietkiewicz E, Rafalski A, Labuda D (1994). Genome fingerprinting by simple sequence repeat (SSR)-anchored polymerase chain reaction amplification. Genomics, 20: 176-183. 